Research Paper

\title{
Has the increase in the regional nodes evaluated improved survival rates for patients with locoregional colon cancer?
}

\author{
Zhongyi Zhou, MD1*; Hong Zhu, MD²; Wenxue Liu, MD3,4; Fengbo Tan, PhD1; Qian Pei, MD1; Lilan Zhao,

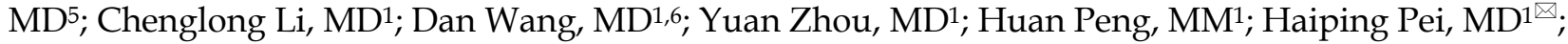 \\ Yuqiang Li, MD ${ }^{1,6}$
}

1. Department of General Surgery, Xiangya Hospital, Central South University, Changsha, China.

2. Department of Radiotherapy, Xiangya Hospital, Central South University, Changsha, China.

3. Department of Cardiology, Xiangya Hospital, Central South University, Changsha, China.

4. Department of Rheumatology, Guangdong Provincial People's Hospital, Guangdong Academy of Medical Sciences, Guangzhou, China.

5. Department of Thoracic surgery, Fujian Provincial Hospital, Fuzhou, China.

6. Department of General Visceral and Thoracic Surgery, University Medical Center Hamburg-Eppendorf, Hamburg, Germany.

*This author contributed mainly to this article as first author.

$\triangle$ Corresponding authors: Haiping Pei, Department of General Surgery, Xiangya Hospital, Central South University, 87 Xiangya Road, Changsha, Hunan, P.R. China; E-mail: peihaiping1966@hotmail.com; Yuqiang Li, Department of General Surgery, Xiangya Hospital, Central South University, 87 Xiangya Road, Changsha, Hunan, P.R. China; Department of General Visceral and Thoracic Surgery, University Medical Center Hamburg-Eppendorf, Martinistraße 52, Hamburg, Germany; E-mail: liyuqiang22@yeah.net.

(c) The author(s). This is an open access article distributed under the terms of the Creative Commons Attribution License (https://creativecommons.org/licenses/by/4.0/). See http://ivyspring.com/terms for full terms and conditions.

Received: 2020.08.24; Accepted: 2021.02.14; Published: 2021.03.05

\begin{abstract}
Background: The guidelines for colon cancer surgery have been evolving over the past three decades. The advances in colectomy have focused mainly on the number of regional nodes evaluated (RNE).

Methods: Data in this retrospective analysis were extracted from the Surveillance, Epidemiology, and End Results (SEER) linked database.

Results: Rapid growth of RNE (the median rising from 10 (6-16) to 17 (13-23)) occurred from 2000 to 2009. The rate of colon cancer patients with positive lymph nodes following colectomy was greatly decreasing only in the group with RNE greater than 12 after 2000. Patients with T4 and/or N+ cannot obtain survival benefit from the increasing trend of RNE. The apparent survival benefit for TI-3NO patients may result from augmented false negatives in patients from previous periods.

Conclusions: The golden period of surgical development in colon cancer, using RNE as an alternative indicator, occurred in the first decade of the 21 st century. Although a more extensive lymph node evaluation is able to reduce the risk of underestimated staging, the increase of RNE does not provide survival benefits for locoregional colon cancer. A proper reduction in the scope of lymph node dissection may be reasonable in radical surgery for colon cancer.
\end{abstract}

Key words: colon cancer; regional nodes evaluated; surgery; surgical evolution; SEER database

\section{Introduction}

The standards for colon cancer surgery have been evolving over the past three decades. The guidelines that were developed at the Sydney World Congress of Gastroenterology in 1990 stated that examination of at least 12 lymph nodes can be used as a benchmark to ensure proper resection and appropriate staging [1-3]. Extended mesenteric excision for colon cancer was first proposed in 1997 [4]. In 2002, the American Joint Committee on Cancer
(AJCC) established the identification of a minimum of 12 lymph nodes as the standard in colon cancer resection, which served as an impetus to increase the number of lymph nodes obtained and analyzed nationwide [5]. Complete mesocolic excision (CME) was initially introduced in 2009 and then widely recognized by colorectal surgeons [6, 7].

Overall, the advances in colectomy mainly involved the number of regional nodes evaluated 
(RNE). Therefore, several studies have reported that the number of RNE has become a surrogate marker for the evaluation of the quality of surgery for patients with colon cancer $[8,9]$. What happened as a result of the trend in RNE during the progress of colectomy in the United States? When was the most rapid development period of colon cancer surgery? In addition, do patients with locoregional colon cancer obtain survival benefit from the changing RNE during the rapid development period? There is no final conclusion yet. Exploration of these issues may provide research directions related to colon cancer, or even all tumors, in the future.

Therefore, this study aimed to explore the trend of RNE from 1988 to 2016 in colectomy surgery for locoregional colon cancer and to compare the survival differences due to the evolution of RNE.

\section{Materials and Methods}

\section{Patients}

Data in this retrospective analysis were extracted from the Surveillance, Epidemiology, and End Results (SEER) linked database. The SEER Program of the National Cancer Institute is an authoritative source of information on cancer incidence and survival in the United States that is updated annually. SEER currently collects and publishes cancer incidence and survival data from population-based cancer registries covering approximately $34.6 \%$ of the U.S. population. Our target population were the patients with Stage I-III colorectal adenocarcinoma after colectomy in the period 1988-2016 ( $\mathrm{n}=383,066)$. Exclusion criteria: (1) without positive histology $(\mathrm{n}=196) ;$ (2) without detailed survival data (including survival months $=0$, diagnosed at autopsy or death certificate) $(n=12,752)$; (3) without detailed information of regional nodes examined (including $\mathrm{RNE}=0$ ) or regional nodes positive $(n=14,949)$; (4) T0 $(n=18)$; leading to a sample of 355,151 patients. The target population for survival analysis was limited to patients in the periods of 1999-2000 and 2010-2011. The third edition AJCC staging was adopted in colorectal cancer in 1999-2000; however, the sixth edition of the AJCC staging was applied to for the patients of 2009-2010. Therefore, we re-staged the $\mathrm{N}$ stage according to the number of positive lymph nodes. We defined N1 as 1-3 lymph nodes positive and N2 as more than 4 lymph nodes positive. The final study sample contained 56,099 patients (Fig. 1).

\section{Methods}

Intergroup comparisons were performed with the Pearson's chi-square test or Mann-Whitney U-test, depending on the nature of the data. Log-rank test was used to compare overall survival (OS) between different groups. A hazard ratio (HR) and a 95\% confidence interval (CI) were evaluated by a single factor and a multivariate Cox proportional hazards regression model. The variables with significant differences in univariate analysis were included in the Cox regression model for multivariate analysis. In order to eliminate the influence of other variables, we conducted a propensity score matching (PSM). The nearest neighbor matching with a caliper width of 0.0001 was employed. Statistical analyses were performed with IBM SPSS statistics trial ver. 25.0 (IBM, Armonk, NY, USA). All reported p-values lower than 0.05 were considered significant.

\section{Results}

\section{The trends of RNE during 1988 to 2016}

Table 1 summarizes the number of cases from 1988 to 2016. There are two platform periods and one growth period displaying the trend of RNE (Fig. 2A). The median number of RNE increased from 9 (5-15) to $10(6-16)$ in the first platform period of 1988-2000. The median of RNE also increased by only one (from 17 (13-23) to 18 (14-24)) in the second platform period (from 2009 to 2016). The rapid growth of RNE (the increase in the median from 10 (6-16) to 17 (13-23)) occurred in the period 2000 to 2009, which suggests that the golden period for the development of surgery was in the first decade of the 21st century (Fig. 2A).

Table 1. The trends of the number of RNE from 1988 to 2016

\begin{tabular}{|c|c|c|c|c|c|c|c|c|}
\hline Year & $\begin{array}{l}\text { No. } \\
\text { of } \\
\text { cases }\end{array}$ & $\begin{array}{l}\text { No. of } \\
\text { stage III } \\
\text { cases }\end{array}$ & $\begin{array}{l}\text { Rate of } \\
\text { stage III }\end{array}$ & $\begin{array}{l}\text { No. of } \\
\text { cases } \\
\text { with } \\
\text { RNE } \\
\geq 12\end{array}$ & $\begin{array}{l}\text { Rate of } \\
\text { cases } \\
\text { with } \\
\text { RNE } \\
\geq 12\end{array}$ & $\begin{array}{l}\text { No. of } \\
\text { stage III } \\
\text { cases } \\
\text { with } \\
\text { RNE } \geq \\
12\end{array}$ & $\begin{array}{l}\text { Rate of } \\
\text { stage III } \\
\text { in cases } \\
\text { with } \\
\text { RNE } \geq \\
12\end{array}$ & RNE \\
\hline 1988 & 4809 & 1643 & $34.17 \%$ & 1803 & $37.49 \%$ & 661 & $36.66 \%$ & $9(5-15)$ \\
\hline 1989 & 4820 & 1616 & $33.53 \%$ & 1797 & $37.28 \%$ & 654 & $36.39 \%$ & $9(5-15)$ \\
\hline 1990 & 5197 & 1737 & $33.42 \%$ & 2031 & $39.08 \%$ & 760 & $37.42 \%$ & $9(5-15)$ \\
\hline 1991 & 5410 & 1796 & $33.20 \%$ & 2182 & $40.33 \%$ & 819 & $37.53 \%$ & $9(5-15)$ \\
\hline 1992 & 7168 & 2441 & $34.05 \%$ & 2728 & $38.06 \%$ & 1062 & $38.93 \%$ & $9(5-15)$ \\
\hline 1993 & 7078 & 2396 & $33.85 \%$ & 2903 & $41.01 \%$ & 1080 & $37.20 \%$ & $10(6-15)$ \\
\hline 1994 & 7226 & 2514 & $34.79 \%$ & 2894 & $40.05 \%$ & 1137 & $39.29 \%$ & $10(6-15)$ \\
\hline 1995 & 7253 & 2604 & $35.90 \%$ & 2875 & $39.64 \%$ & 1159 & $40.31 \%$ & $10(6-15)$ \\
\hline 1996 & 7422 & 2546 & $34.30 \%$ & 3107 & $41.86 \%$ & 1219 & $39.23 \%$ & $10(6-16)$ \\
\hline 1997 & 7803 & 2730 & $34.99 \%$ & 3371 & $43.20 \%$ & 1340 & $39.75 \%$ & $10(6-16)$ \\
\hline 1998 & 8224 & 2796 & $34.00 \%$ & 3574 & $43.46 \%$ & 1397 & $39.09 \%$ & $10(6-16)$ \\
\hline 1999 & 8160 & 2735 & $33.52 \%$ & 3609 & $44.23 \%$ & 1352 & $37.46 \%$ & $10(6-16)$ \\
\hline 2000 & 16721 & 5776 & $34.54 \%$ & 7247 & $43.34 \%$ & 2812 & $38.80 \%$ & $10(6-16)$ \\
\hline 2001 & 17275 & 5895 & $34.12 \%$ & 7956 & $46.05 \%$ & 3102 & $38.99 \%$ & $11(7-16)$ \\
\hline 2002 & 17314 & 6004 & $34.68 \%$ & 8421 & $48.64 \%$ & 3330 & $39.54 \%$ & $11(7-17)$ \\
\hline 2003 & 17180 & 5981 & $34.81 \%$ & 8711 & $50.70 \%$ & 3390 & $38.92 \%$ & $12(7-18)$ \\
\hline 2004 & 16833 & 5816 & $34.55 \%$ & 9111 & $54.13 \%$ & 3489 & $38.29 \%$ & $12(8-18)$ \\
\hline 2005 & 16242 & 5665 & $34.88 \%$ & 9549 & $58.79 \%$ & 3650 & $38.22 \%$ & $13(8-19)$ \\
\hline 2006 & 16673 & 5672 & $34.02 \%$ & 10738 & $64.40 \%$ & 4014 & $37.38 \%$ & $14(9-20)$ \\
\hline 2007 & 16783 & 5922 & $35.29 \%$ & 12264 & $73.07 \%$ & 4665 & $38.04 \%$ & $16(11-22)$ \\
\hline 2008 & 16905 & 5925 & $35.05 \%$ & 13083 & $77.39 \%$ & 4810 & $36.77 \%$ & $16(12-22)$ \\
\hline 2009 & 16411 & 5773 & $35.18 \%$ & 13341 & $81.29 \%$ & 4929 & $36.95 \%$ & $17(13-23)$ \\
\hline 2010 & 15749 & 5514 & $35.01 \%$ & 12989 & $82.48 \%$ & 4737 & $36.47 \%$ & $17(13-23)$ \\
\hline 2011 & 15469 & 5359 & $34.64 \%$ & 12982 & $83.92 \%$ & 4762 & $36.68 \%$ & $17(13-23)$ \\
\hline 2012 & 15496 & 5351 & $34.53 \%$ & 13296 & $85.80 \%$ & 4861 & $36.56 \%$ & $17(13-23)$ \\
\hline 2013 & 15261 & 5385 & $35.29 \%$ & 13368 & $87.60 \%$ & 4868 & $36.42 \%$ & $18(14-24)$ \\
\hline
\end{tabular}




\begin{tabular}{|c|c|c|c|c|c|c|c|c|}
\hline Year & $\begin{array}{l}\text { No. } \\
\text { of } \\
\text { cases }\end{array}$ & $\begin{array}{l}\text { No. of } \\
\text { stage III } \\
\text { cases }\end{array}$ & $\begin{array}{l}\text { Rate of } \\
\text { stage III }\end{array}$ & $\begin{array}{l}\text { No. of } \\
\text { cases } \\
\text { with } \\
\text { RNE } \\
\geq 12\end{array}$ & $\begin{array}{l}\text { Rate of } \\
\text { cases } \\
\text { with } \\
\text { RNE } \\
\geq 12\end{array}$ & $\begin{array}{l}\text { No. of } \\
\text { stage III } \\
\text { cases } \\
\text { with } \\
\text { RNE } \geq \\
12\end{array}$ & $\begin{array}{l}\text { Rate of } \\
\text { stage III } \\
\text { in cases } \\
\text { with } \\
\text { RNE } \geq \\
12\end{array}$ & RNE \\
\hline 2014 & 15429 & 5319 & $34.47 \%$ & 13754 & $89.14 \%$ & 4880 & $35.48 \%$ & $18(14-24)$ \\
\hline 2015 & 15053 & 5268 & $35.00 \%$ & 13518 & $89.80 \%$ & 4828 & $35.72 \%$ & $18(14-24)$ \\
\hline 2016 & 13787 & 4767 & $34.58 \%$ & 12526 & $90.85 \%$ & 4416 & $35.25 \%$ & $18(14-24)$ \\
\hline
\end{tabular}

Increasing RNE did not cause a significant rise in the proportion of patients with stage III colon cancer. In fact, the rate of colon cancer patients with positive lymph nodes had greatly decreased after 2000 when only comparing patients with RNE greater than 12 (Fig. 2B). The obvious changes attracted us to compare survival differences between 1999-2000 with those in 2010-2011, as described in the following section.

\section{Cox regression analysis}

In this section, which includes cases with locoregional colon cancer from 1999-2000 and 2010-2011, the focus was on comparing survival differences due to the rising trend of RNE. Table 2 displays the characteristics of the patients in this section. There was significant difference in RNE between the two periods. The Cox regression analysis did not include RNE because it could have interfered with results caused by the changing trend. Meanwhile, the year of diagnosis was used as a variable to replace the trend of RNE. Moreover, the significant variables in the univariate analysis were brought into the multivariate analysis.

The total cohort and the four subgroups, including T1-3N0, T4N0, T1-3N+ and $\mathrm{T} 4 \mathrm{~N}+$, were analyzed separately for all patients. Table S1 shows the detailed results in the univariable and multivariable Cox regression model of all locoregional colon cancer patients in the two periods. Fig. 3A summarizes the survival differences by the year of diagnosis. Locoregional colon cancer patients from 2010-2011, as an entirety, had better survival than those from 1999-2000. Meanwhile, the subgroup analysis displayed that colon cancer patients with T1-3N0 and $\mathrm{T}_{\mathrm{any}} \mathrm{N}+$ from 2010-2011 had superior survival to those from 1999-2000. However, there was no significant difference between the two periods in the colon cancer patients with T4N0.

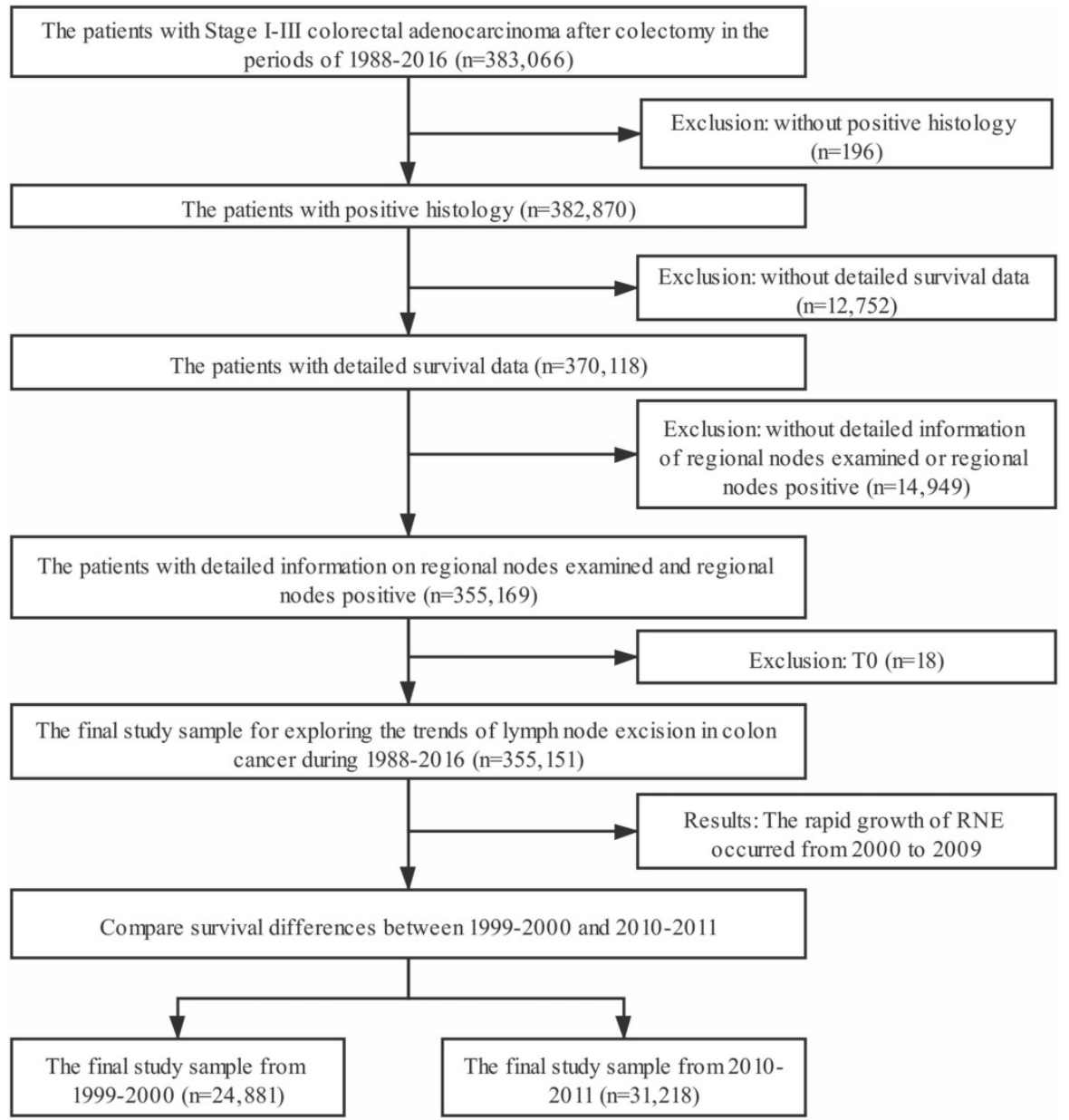

Figure 1. The flow chart. Inclusion criteria: the patients with Stage I-III colorectal adenocarcinoma after colectomy in the period 1988-2016 ( $=383,066)$. Exclusion criteria: (1) without positive histology $(n=196)$; (2) without detailed survival data (including survival months=0, diagnosed at autopsy or death certificate) ( $n=12,752)$; (3) without detailed information of regional nodes examined (including RNE=0) or regional nodes positive $(n=14,949)$; $(4)$ T0 $(n=18)$. 

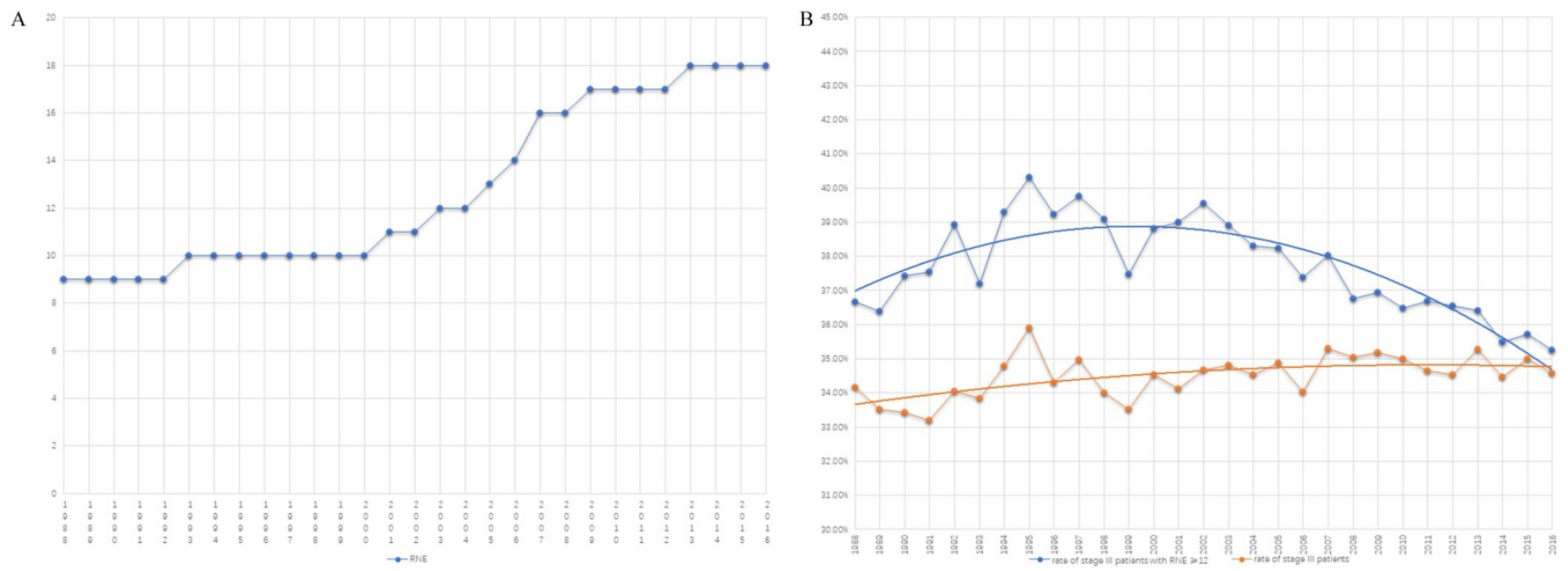

Figure 2. The trend graph. A) The trend of the number of RNE from 1988-2016. B) The trend of the rate of colon cancer patients with positive lymph nodes (orange line: the proportion of the entire patients with stage III colon cancer; blue line: the rate of colon cancer patients with positive lymph nodes in those with RNE $\geq 12$ ).

A

Subgroup

Total cohort

T1-3N0

T4NO*

$\mathrm{T} 1-3 \mathrm{~N}+$

$\mathrm{T} 4 \mathrm{~N}+$

${ }^{*}$ No difference in univariate analysis

$\mathrm{B}$

Subgroup

Total cohort

T1-3N0

T4NO*

$\mathrm{T} 1-3 \mathrm{~N}+*$

$\mathrm{T} 4 \mathrm{~N}+^{*}$

$\mathrm{HR}(95 \% \mathrm{Cl})$

$0.898(0.875-0.922)$

0.906(0.873-0.941)

NA

$0.876(0.836-0.918)$

0.859(0.792-0.931)

$\mathrm{HR}(95 \% \mathrm{Cl})$

0.933(0.905-0.962)

0.901(0.867-0.937)

NA

NA

NA

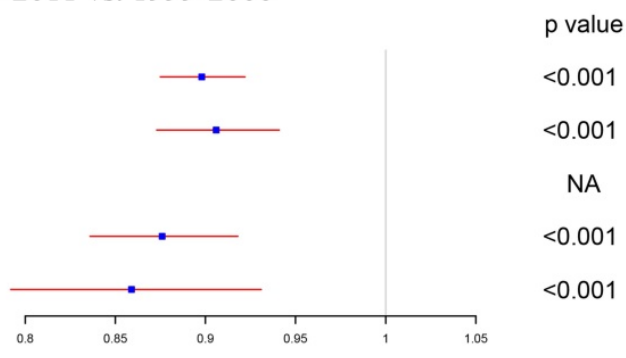

2010-2011 vs. $1999-2000$

2010-2011 vs. 1999-2000

$<0.001$

0.001

0.001

$p$ value

$<0.001$

$<0.001$

NA

NA

NA

*No difference in univariate analysis

Figure 3. The survival differences in multivariate COX regression analysis (2010-2011 vs. 1999-2000). A. The survival differences of the year of diagnosis in all locoregional colon cancer patients. B. The survival differences of the year of diagnosis in locoregional colon cancer patients without chemotherapy.

In order to rule out the impact of the advances in chemotherapy, we further analyzed those patients who did not receive chemotherapy. Table S2 indicates the exhaustive results of the univariable and multivariable Cox regression model for patients without chemotherapy. Similar to the total group results, locoregional colon cancer patients without chemotherapy from 2010-2011 had better survival than those from 1999-2000 in the analysis of this cohort. However, only T1-3N0 patients without chemotherapy can obtain survival benefit from the increased RNE in the subgroup analysis (Fig. 3B).

\section{Propensity score matching}

In order to verify the results of the Cox regression analysis, we conducted propensity score matching (PSM) to eliminate the influence of other variables. Table S3 illustrates the characteristics of all the patients with locoregional colon cancer following PSM. The number of RNE, which can reflect the quality of surgery, did not match between the two periods. Differences in survival before PSM were similar to those after PSM in both the total cohort and the subgroups (Figs. 4 and 5). The total cohort received survival benefit from the increased RNE. Colon cancer patients with $\mathrm{T} 1-3 \mathrm{~N} 0$ and $\mathrm{T}_{\text {any }} \mathrm{N}+$ from 1999-2000 suffered a worse survival compared with those from 2010-2011. However, T4N0 colon cancer patients did not obtain survival benefit from the increased RNE either before $(p=0.501)$ or after PSM $(\mathrm{p}=0.456)$. 

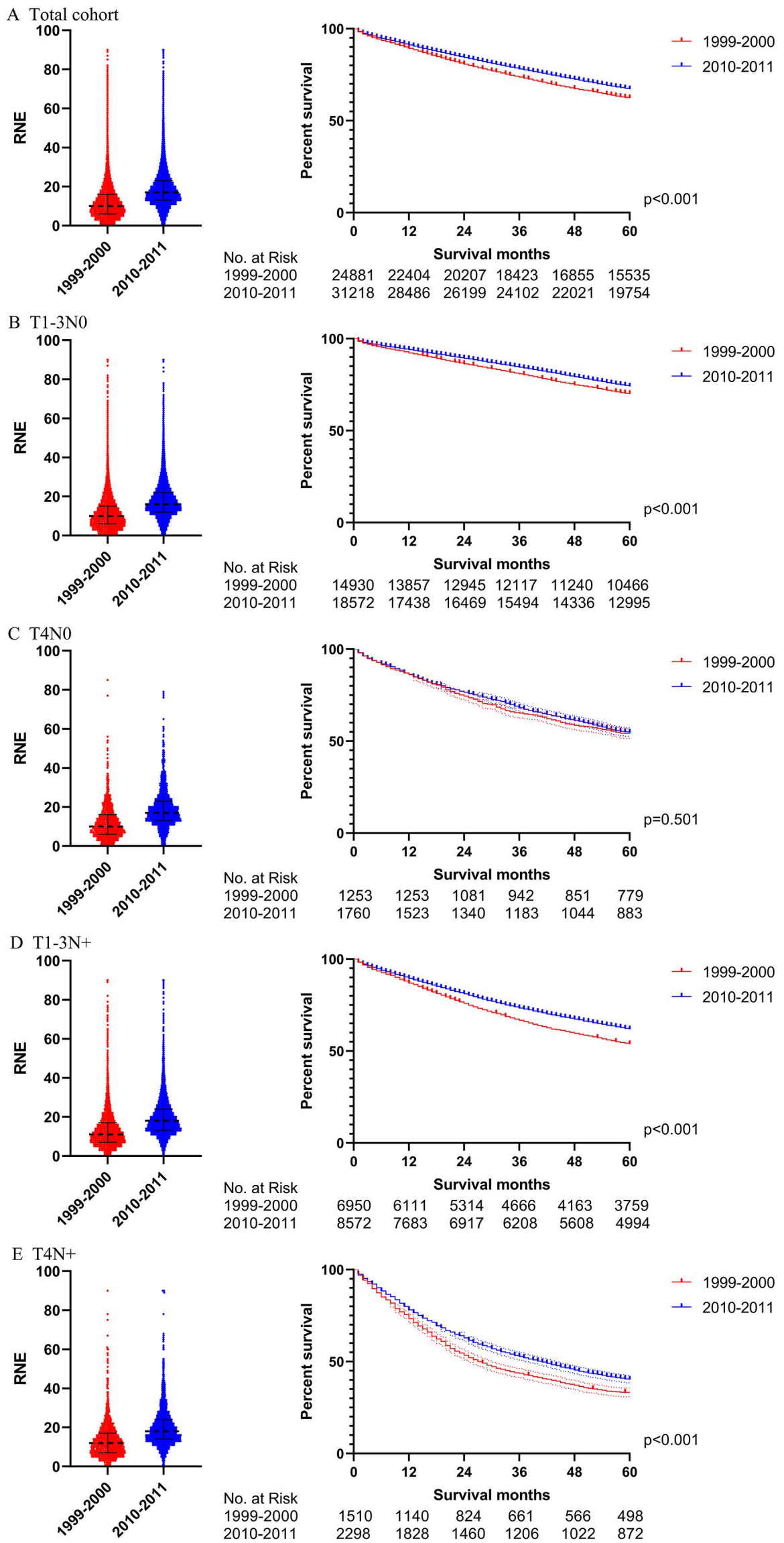

Figure 4. The survival analysis before PSM in all locoregional colon cancer patients (left: RNE of each patient, all $p<0.001$; right: survival curve). A. The total cohort. B. T1-3NO. C. T4NO. D. T1-3N+. E. T4N+. 
A Total cohort

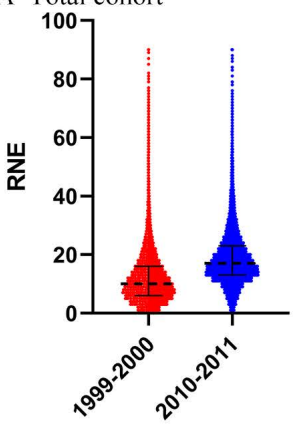

B $\mathrm{T} 1-3 \mathrm{~N} 0$

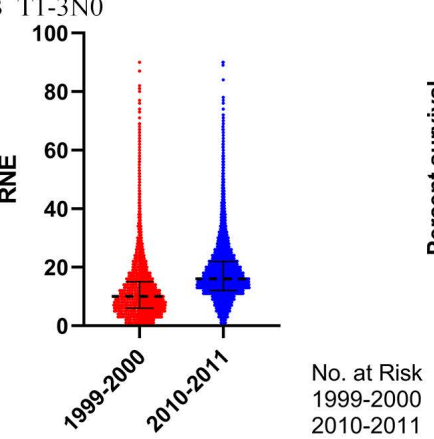

C T4N0

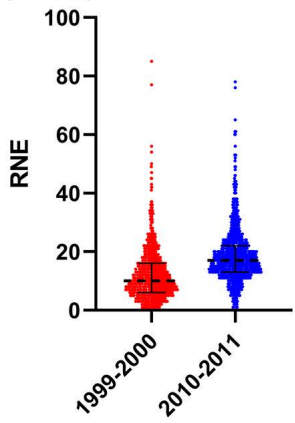

D $\mathrm{T} 1-3 \mathrm{~N}+$

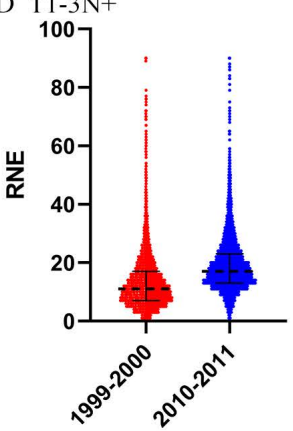

E T4N+

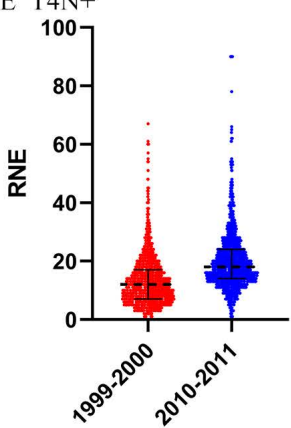

1999-2000 2010-2011

2010-2011

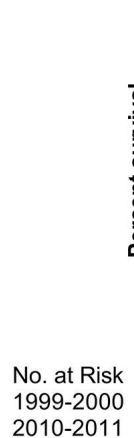

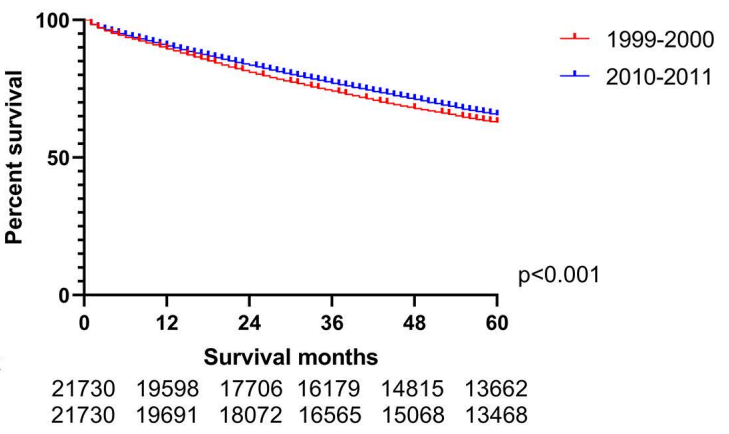

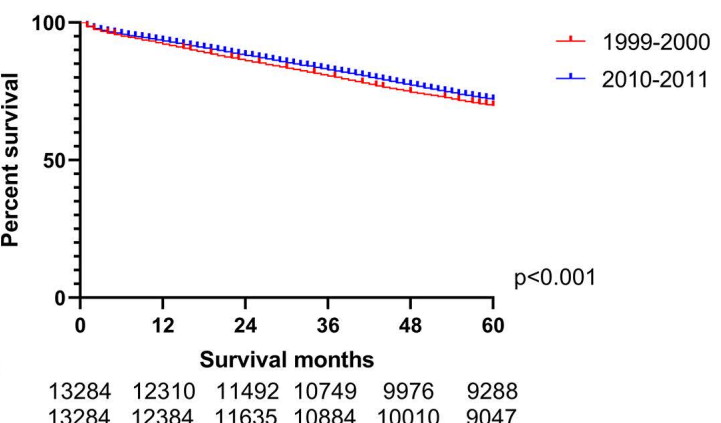

$\begin{array}{llllll}13284 & 12384 & 11635 & 10884 & 10010 & 9047\end{array}$

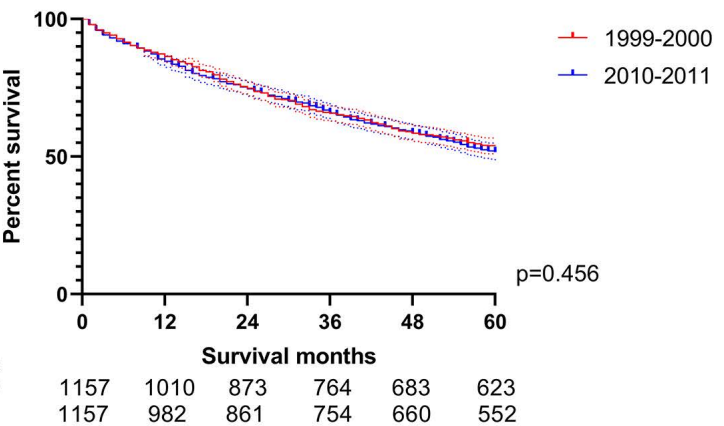

$\begin{array}{llllll}1157 & 982 & 861 & 754 & 660 & 552\end{array}$
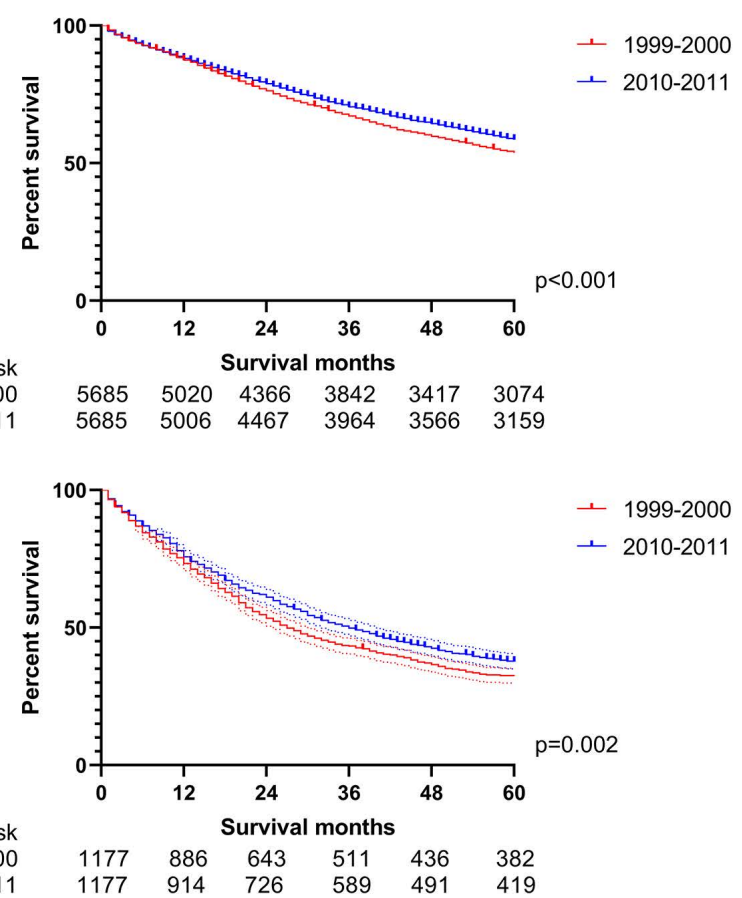

Figure 5. The survival analysis after PSM in all locoregional colon cancer patients (left: RNE of each patient, all $\mathrm{p}<0.001$; right: survival curve). A. The total cohort. B. T1-3N0. C. T4N0. D. T1-3N+. E. T4N+ 
Then we further analyzed the locoregional colon cancer patients without chemotherapy. Table S4 describes the characteristics of the patients without chemotherapy after PSM. The results after PSM were consistent with those before PSM (Figs. 6 and 7). Locoregional colon cancer patients without chemotherapy from 2010-2011 showed a superior survival rate in the total cohort analysis. There were significant survival differences in colon cancer patients with T1-3N0 who did not receive chemotherapy between the two periods ( $p<0.001$ both before and after PSM). However, patients with T4 and/or N+ who missed chemotherapy did not obtain survival benefit from the increasing trend of RNE either before or after PSM.

\section{Further analysis of T1-3N0 patients with RNE greater than 12}

We also utilized Cox regression analysis and propensity score matching to explore whether T1-3N0 patients with RNE greater than 12 from 2010-2011 could achieve a winning survival compared to those from 1999-2000. Table 3 displays the characteristics of the T1-3N0 patients with RNE greater than 12 from 1999-2000 and from 2010-2011. The RNE of patients from 2010-2011 was slightly larger than that from 1999-2000 (18 (15-24) vs. 17(14-23), $\mathrm{p}<0.001)$. However, the multivariate Cox regression analysis, for both of the entire patient group $(p=0.138)$ and patients without chemotherapy $(p=0.091)$, did not demonstrate significant differences between the two periods (Table S5). Table S6 illustrates the characteristics of the T1-3N0 patients with RNE $\geq 12$ after PSM. Survival differences between 1999-2000 and 2010-2011 tapered from significant differences before PSM (both the entire group of patients and patients without chemotherapy: $p \quad<0.001$ ) to insignificant after PSM (the entire group of patients: $\mathrm{p}=0.543$; the patients without chemotherapy: $\mathrm{p}=0.307$ ) (Fig. 8).

\section{Discussion}

This population-based study confirmed one growth period and two platform periods regarding the trend in the number of RNE during colectomy for locoregional colon cancer in the past decades. The rapidly growing RNE revealed that the period from 2000 to 2009 was the golden phase of the development of colon cancer surgery. Previous research has reported that increasing RNE was not able to improve the staging of colon cancer [5]. However, this study believes that improvements in colorectal cancer screening and early detection can lead to patients being diagnosed at an earlier stage than in previous years because the proportion of patients with colon cancer with positive lymph nodes showed a downward trend in patients with RNE greater than 12, which allows assessing lymph node staging more accurately [10]. Moreover, although several previous studies reported that RNE showed an increasing trend in colectomy, they failed to discuss the impact of this tendency on survival for colon cancer [8, 11-14]. Collectively, these changes attracted us to explore the survival differences before and after the golden period of colon cancer surgery. Therefore, this study focused on comparing survival differences between patients from the period 1999-2000, as a baseline, to 2010-2011, which included patients with the most recent 5-year follow-up.

Table 2. The characteristics of colon cancer patients in 1999-2000 and 2010-2011

\begin{tabular}{|c|c|c|c|c|c|}
\hline \multirow[t]{2}{*}{ Characteristics } & \multicolumn{2}{|c|}{$1999-2000(n=24881)$} & \multicolumn{2}{|c|}{$2010-2011(n=31218)$} & \multirow[t]{2}{*}{$\mathrm{p}$} \\
\hline & $\overline{\mathrm{N}}$ & $\%$ & $\mathrm{~N}$ & $\%$ & \\
\hline Gender & & & & & 0.008 \\
\hline Female & 13066 & $52.51 \%$ & 16042 & $51.39 \%$ & \\
\hline Male & 11816 & $47.49 \%$ & 15176 & $48.61 \%$ & \\
\hline Age (years) & & & & & $<0.001$ \\
\hline$\leq 50$ & 1881 & $7.56 \%$ & 3156 & $10.11 \%$ & \\
\hline $51-65$ & 5626 & $22.61 \%$ & 8865 & $28.40 \%$ & \\
\hline$>65$ & 17374 & $69.83 \%$ & 19197 & $61.49 \%$ & \\
\hline Marital status & & & & & 0.017 \\
\hline Married & 13359 & $53.69 \%$ & 16446 & $52.68 \%$ & \\
\hline Unmarried/NOS & 11522 & $46.31 \%$ & 14772 & $47.32 \%$ & \\
\hline Race & & & & & $<0.001$ \\
\hline White & 20768 & $83.47 \%$ & 24896 & $79.75 \%$ & \\
\hline Black & 2373 & $9.54 \%$ & 3652 & $11.70 \%$ & \\
\hline Other/NOS & 1740 & $6.99 \%$ & 2670 & $8.55 \%$ & \\
\hline Tumor location & & & & & $<0.001$ \\
\hline Right colon & 14981 & $60.21 \%$ & 19385 & $62.10 \%$ & \\
\hline Left colon & 9522 & $38.27 \%$ & 11332 & $36.30 \%$ & \\
\hline NOS & 378 & $1.52 \%$ & 501 & $1.60 \%$ & \\
\hline Pathological grade & & & & & $<0.001$ \\
\hline $\mathrm{I} / \mathrm{II}$ & 19055 & $76.58 \%$ & 24521 & $78.55 \%$ & \\
\hline III/IV & 4951 & $19.90 \%$ & 5807 & $18.60 \%$ & \\
\hline Unknown & 875 & $3.52 \%$ & 890 & $2.85 \%$ & \\
\hline Histological type & & & & & $<0.001$ \\
\hline Adenocarcinomas & 21279 & $85.52 \%$ & 27999 & $89.69 \%$ & \\
\hline MCC/SRCC & 3602 & $14.48 \%$ & 3219 & $10.31 \%$ & \\
\hline T stage & & & & & $<0.001$ \\
\hline $\mathrm{T} 1$ & 2952 & $11.86 \%$ & 4809 & $15.40 \%$ & \\
\hline $\mathrm{T} 2$ & 3964 & $15.93 \%$ & 5258 & $16.84 \%$ & \\
\hline T3 & 14964 & $60.14 \%$ & 17077 & $54.70 \%$ & \\
\hline $\mathrm{T} 4$ & 2949 & $11.85 \%$ & 4058 & $13.00 \%$ & \\
\hline $\mathrm{Tx}$ & 52 & $0.21 \%$ & 16 & $0.05 \%$ & \\
\hline N stage & & & & & 0.001 \\
\hline No & 16370 & $65.79 \%$ & 20333 & $65.13 \%$ & \\
\hline N1 & 5788 & $23.26 \%$ & 7074 & $22.66 \%$ & \\
\hline N2 & 2723 & $10.94 \%$ & 3811 & $12.21 \%$ & \\
\hline Chemotherapy & & & & & 0.002 \\
\hline Yes & 6599 & $26.52 \%$ & 8645 & $27.69 \%$ & \\
\hline No & 18282 & $73.48 \%$ & 22573 & $72.31 \%$ & \\
\hline RNE & $10(6-16)$ & & $17(13-23)$ & & $<0.001$ \\
\hline
\end{tabular}

MCC: mucinous cell carcinoma; SRCC: signet ring cell carcinoma; NOS: not otherwise specified. 
A Total cohort

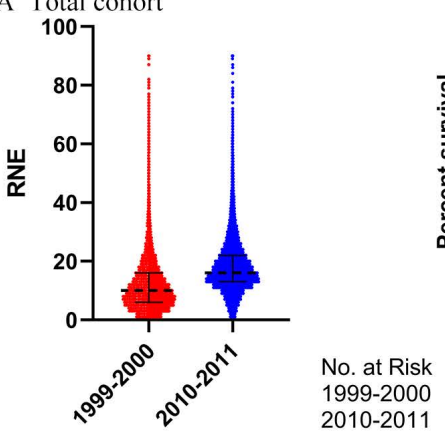

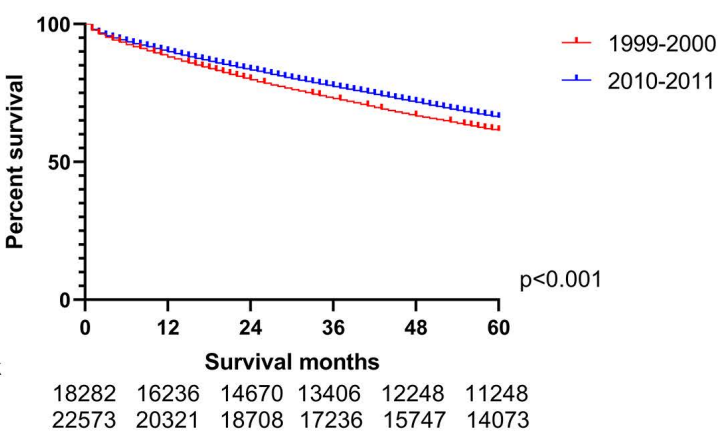

B T1-3NO
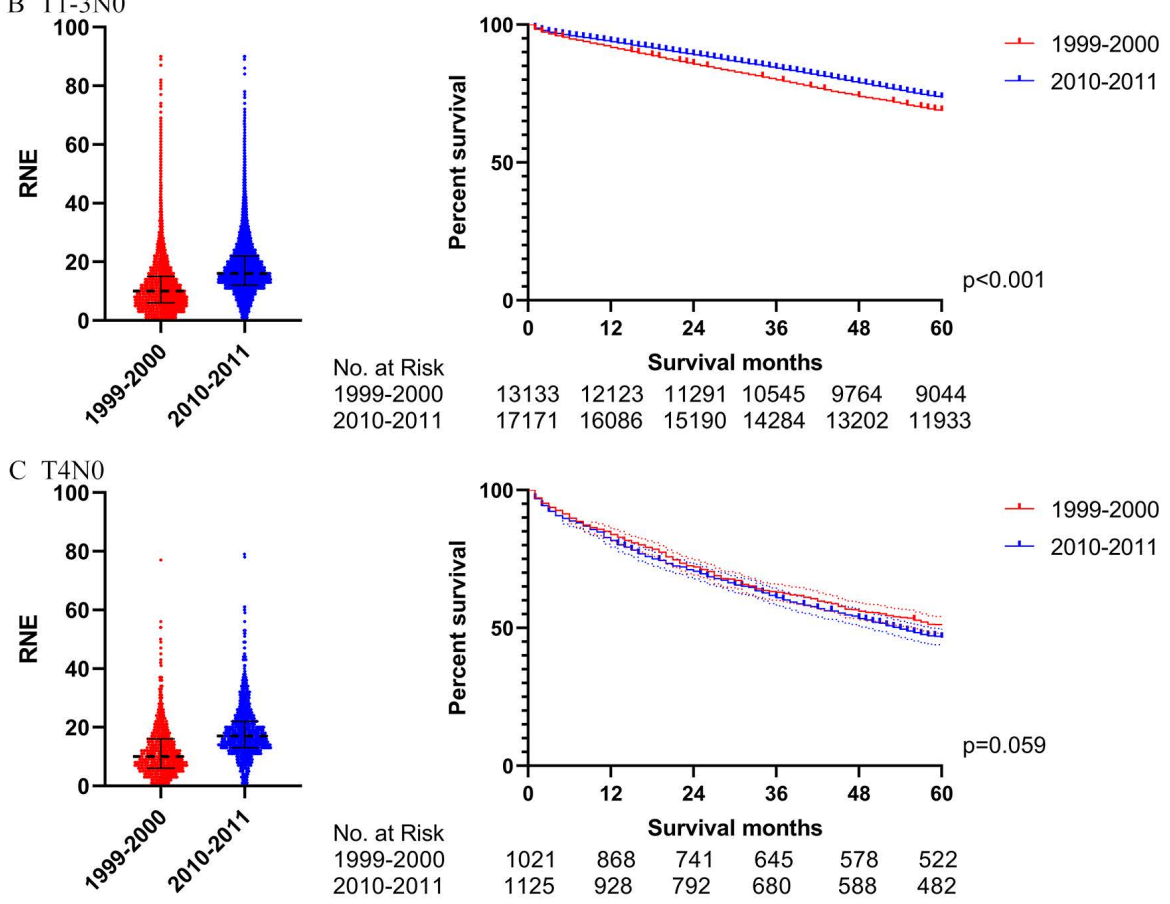

D $\mathrm{T} 1-3 \mathrm{~N}+$
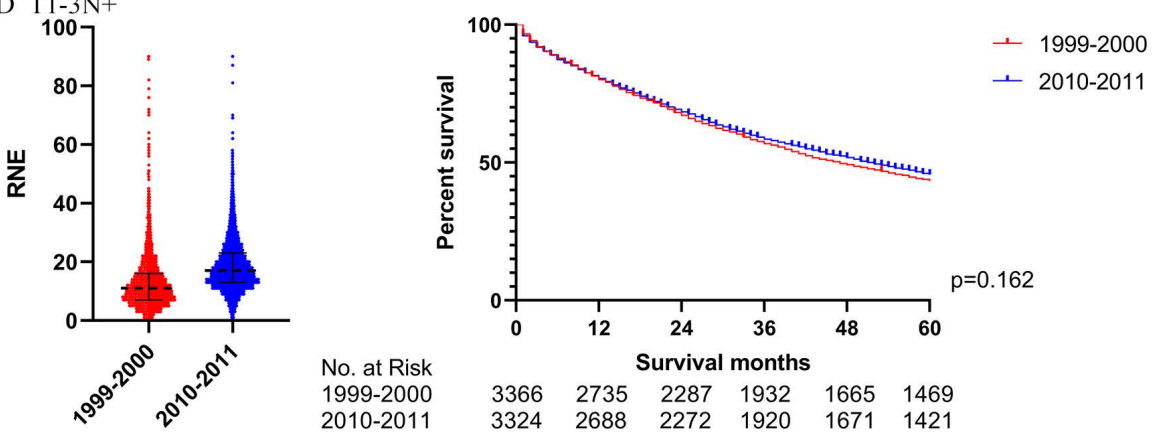

E T4N+
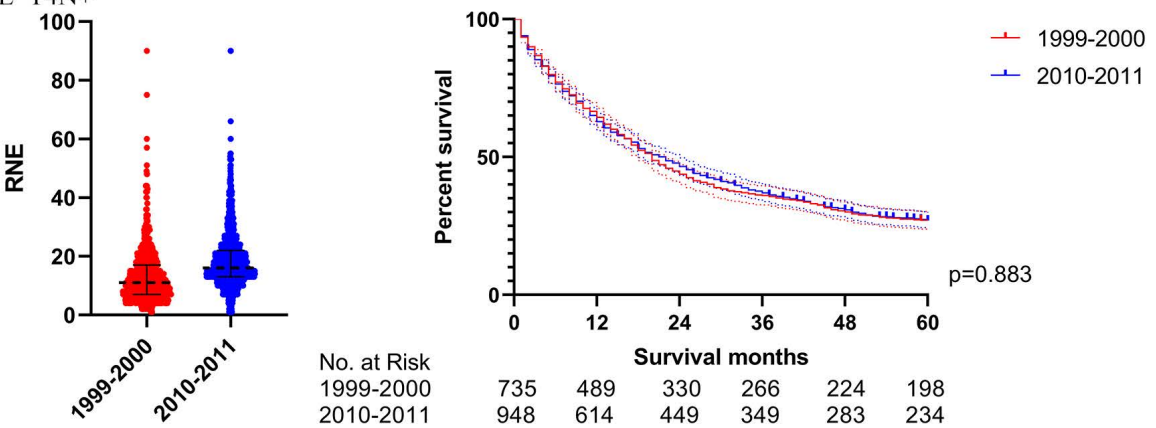

Figure 6. The survival analysis before PSM in locoregional colon cancer patients without chemotherapy (left: RNE of each patient, all p<0.001; right: survival curve). A. The total cohort. B. T1-3N0. C. T4N0. D. T1-3N+. E. T4N+. 

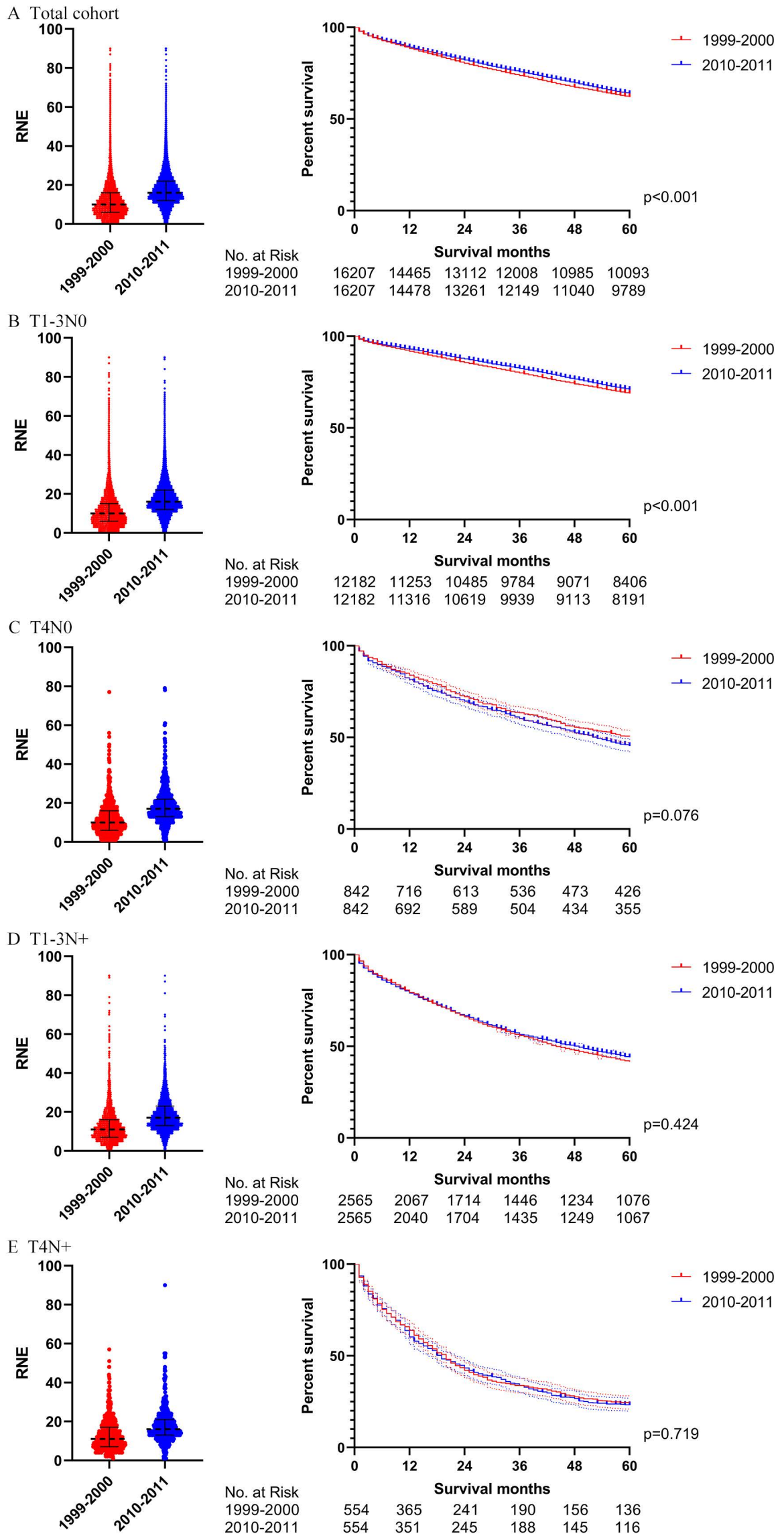

Figure 7. The survival analysis before PSM in locoregional colon cancer patients without chemotherapy (left: RNE of each patient, all p $<0.001$; right: survival curve). A. The total cohort. B. TI-3NO. C. T4NO. D. T1-3N+. E. T4N+. 
A T1-3N0 patients with RNE $\geq 12$ befor PSM
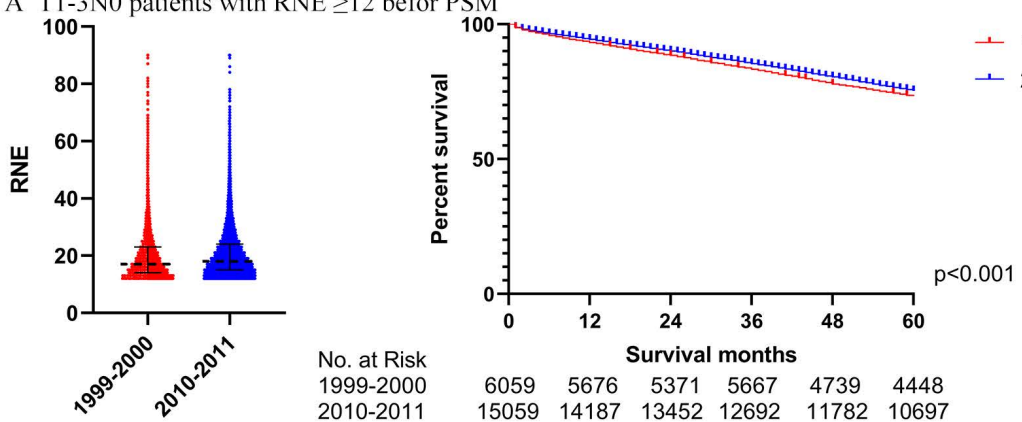

B T1-3N0 patients with RNE $\geq 12$ after PSM

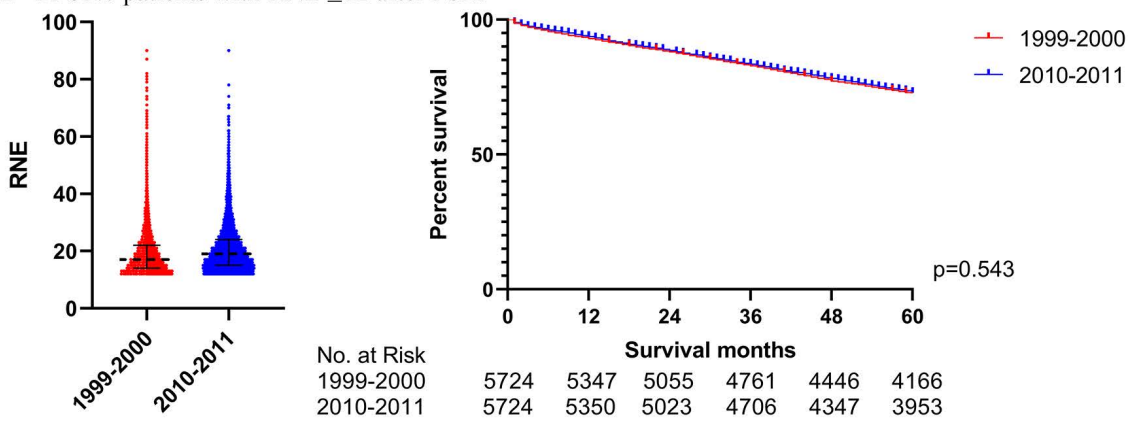

C T1-3N0 patients with RNE $\geq 12$ who did not receive chemotherapy before PSM

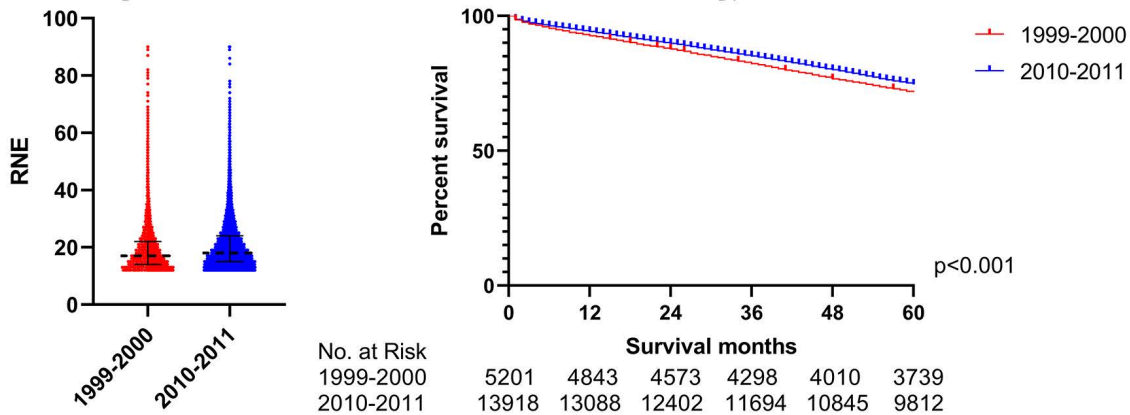

D T1-3N0 patients with RNE $\geq 12$ who did not receive chemotherapy after PSM

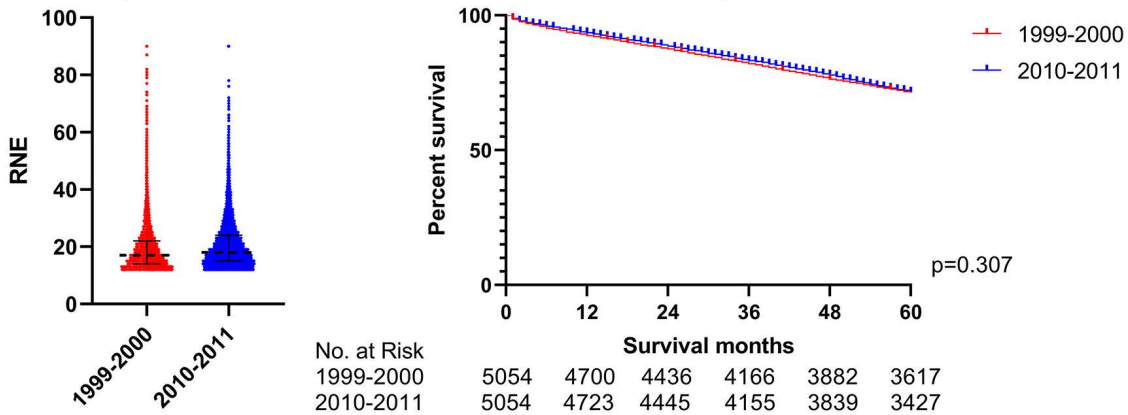

Figure 8. The survival analysis in TI-3N0 colon cancer patients with RNE $\geq 12$ (left: RNE of each patient, all p $<0.001$; right: survival curve). A. TI-3N0 colon cancer patients with RNE $\geq 12$ before PSM. B. T1-3N0 colon cancer patients with RNE $\geq 12$ after PSM. C. T1-3N0 colon cancer patients with RNE $\geq 12$ who did not receive chemotherapy before PSM. D. TI-3NO colon cancer patients with RNE $\geq 12$ who did not receive chemotherapy after PSM.

An increasing number of studies, making horizontal comparisons, have reported better survival for patients with more lymph nodes evaluated among those surgically treated for colon cancer [15-17]. Our study, longitudinally comparing survival differences associated with greater RNE, seems to support this viewpoint that patients with locoregional colon cancer from 2010-2011 achieved superior survival to those from 1999-2000 in the analysis of the total cohort.
However, this conclusion is due to the fact that $\mathrm{T} 1-3 \mathrm{~N} 0$, representing the vast majority of locoregional colon cancer, masked the situation that locally advanced colon cancer ( $\mathrm{T} 4$ and/or $\mathrm{N}+$ ) cannot obtain benefit from increasing RNE. Research without subgroup analysis $[8,18]$ may come to such erroneous conclusions. Moreover, studies that analyze patients with stage II colon cancer as a whole [19], may also miss the true condition of T4N0 patients. Meanwhile, 
patients with stage III colon cancer were able to gain survival benefit from the advanced chemotherapy regimen, evolving from 5-FU/leucovorin in the 1999-2000 [20] to FOLFOX (oxaliplatin/5-FU/ leucovorin) in 2010-2011 [9], demonstrated in this study by the significant survival differences that appeared in the overall analysis of stage III but not in those patients who did not receive chemotherapy. An analysis of the SEER database also supported that advancements in chemotherapy were the main contributor to the upswing in the survival of locally advanced colon cancer [9]. Unfortunately, patients with T4N0 did not acquire survival benefits from the improved chemotherapy and surgery. Therefore, patients with T4N0, who actually suffered worse survival compared to those with IIIA stage colon cancer [21], should gain more attention in future clinical practice.

Table 3. The Characteristics of the T1-3N0 patients with RNE greater than 12 in 1999-2000 and 2010-2011

\begin{tabular}{|c|c|c|c|c|c|}
\hline \multirow[t]{2}{*}{ Characteristics } & \multicolumn{2}{|c|}{$1999-2000(n=6059)$} & \multicolumn{2}{|c|}{$2010-2011(n=15059)$} & \multirow[t]{2}{*}{$p$} \\
\hline & $\bar{N}$ & $\%$ & $\mathrm{~N}$ & $\%$ & \\
\hline Gender & & & & & 0.027 \\
\hline Female & 3253 & $53.69 \%$ & 7832 & $52.01 \%$ & \\
\hline Male & 2806 & $46.31 \%$ & 7227 & $47.99 \%$ & \\
\hline Age (years) & & & & & $<0.001$ \\
\hline$\leq 50$ & 527 & $8.70 \%$ & 1311 & $8.71 \%$ & \\
\hline $51-65$ & 1346 & $22.21 \%$ & 4171 & $27.70 \%$ & \\
\hline$>65$ & 4186 & $69.09 \%$ & 9577 & $63.60 \%$ & \\
\hline Marital status & & & & & 0.780 \\
\hline Married & 3218 & $53.11 \%$ & 8030 & $53.32 \%$ & \\
\hline Unmarried/NOS & 2841 & $46.89 \%$ & 7029 & $46.68 \%$ & \\
\hline Race & & & & & $<0.001$ \\
\hline White & 5126 & $84.60 \%$ & 12279 & $81.54 \%$ & \\
\hline Black & 550 & $9.08 \%$ & 1666 & $11.06 \%$ & \\
\hline Other/NOS & 383 & $6.32 \%$ & 1114 & $7.40 \%$ & \\
\hline Tumor location & & & & & 0.001 \\
\hline Right colon & 4233 & $69.86 \%$ & 10084 & $66.96 \%$ & \\
\hline Left colon & 1725 & $28.47 \%$ & 4785 & $31.78 \%$ & \\
\hline NOS & 101 & $1.67 \%$ & 190 & $1.26 \%$ & \\
\hline Pathological grade & & & & & $<0.001$ \\
\hline $\mathrm{I} / \mathrm{II}$ & 4806 & $79.32 \%$ & 12632 & $83.88 \%$ & \\
\hline III/IV & 1064 & $17.56 \%$ & 2005 & $13.31 \%$ & \\
\hline Unknown & 189 & $3.12 \%$ & 422 & $2.80 \%$ & \\
\hline Histological type & & & & & $<0.001$ \\
\hline Adenocarcinomas & 5186 & $85.59 \%$ & 13680 & $90.84 \%$ & \\
\hline MCC/SRCC & 873 & $14.41 \%$ & 1379 & $9.16 \%$ & \\
\hline T stage & & & & & $<0.001$ \\
\hline $\mathrm{T} 1$ & 713 & $11.77 \%$ & 2935 & $19.49 \%$ & \\
\hline $\mathrm{T} 2$ & 1258 & $20.76 \%$ & 3514 & $23.33 \%$ & \\
\hline $\mathrm{T} 3$ & 4088 & $67.47 \%$ & 8610 & $57.18 \%$ & \\
\hline Chemotherapy & & & & & $<0.001$ \\
\hline Yes & 858 & $14.16 \%$ & 1141 & $7.58 \%$ & \\
\hline No & 5201 & $85.84 \%$ & 13918 & $92.42 \%$ & \\
\hline RNE & $17(14-23)$ & & $18(15-24)$ & & $<0.001$ \\
\hline
\end{tabular}

In addition, the reason that $\mathrm{T} 1-3 \mathrm{~N} 0$ patients received survival benefit from the increasing RNE may also be due to higher increased false negatives in patients from 1999 to 2000 . A more extensive lymph node evaluation is able to reduce the risk of underestimated staging, in which inadequate assessment may incorrectly identify patients with node-positive disease as node-negative, resulting in failure to identify appropriate treatment. In 1999-2000, the proportion of patients with positive lymph nodes among those with RNE greater than 12 was much larger than that among the overall group. In fact, such a difference gradually decreased after 2000. The proportion of patients with RNE fewer than 12 reached $56.37 \%$ in 1999-2000, which may have caused the proportion of patients with lymph node-positive to be greatly underestimated. Furthermore, the additional analysis involving the patients with RNE greater than 12 showed that real T1-3N0 patients from 2010-2011 did not have superior survival compared to those from 1999-2000. Therefore, it is reasonable that the real T1-3N0 patients will not benefit from the advancements of surgery.

Increasing RNE played an important role in accurate assessment of the $\mathrm{N}$ stage of colon cancer. However, too much RNE is not able to provide better long-term survival, or even reduce the short-term survival [9]. Unfortunately, there is always a constant emphasis on extensive lymph node evaluation during the evolution of colon cancer surgery. However, several scholars have begun to question whether expanding lymph node dissection, including the concept of $\mathrm{CME}$, is better than traditional $\mathrm{D} 2$ resection [22]. Another controversy about aggressive D3 resection versus imperturbable D2 resection has appeared in the radical operation of gastric cancer. The measurement of surgical risk and survival benefit promoted that D2 resection should be the standard procedure for gastric cancer. The experiences from gastric cancer suggest that properly reducing the scope of lymph node dissection may be reasonable for radical surgery in colon cancer.

Numerous surgeons would rather kill more negative nodes instead of missing even one positive node during the radical surgery for colon cancer, which is one of the reasons why CME surgery has been recognized widely. However, the increasing RNE cannot provide survival benefit to colon patients including those with positive nodes. Can the serious consequences of missing metastatic lymph nodes be compensated for by chemotherapy? The fact that neoadjuvant chemotherapy may lead to the downstaging of a part of colon cancer supports that chemotherapy is capable of killing cancer cells in regional lymph nodes. Meanwhile, combination chemotherapy can improve the pathological complete response rate of colorectal cancer [23, 24]. Therefore, advanced chemotherapy, but not advancements in colectomy, can better compensate for the consequences of missing positive lymph nodes. In 
fact, colon cancer with positive lymph nodes should be regarded as a systemic disease that cannot be cured by surgery alone. Advances in chemotherapy regimens are able to provide a better rationale for properly reducing the scope of lymph node dissection.

Although population-based studies such as this offer increased statistical power and generalizability of results, this study was limited by lack of data on comorbidities and clinical presentation of the patient (i.e. cancer found on screening or due to symptoms). There were several limitations in the SEER database such as unrecorded variables, incomplete data regarding detailed adjuvant therapy, variations in the way of recording data, and migration of patients into and out of SEER registry areas. Furthermore, various studies from different countries have also displayed an increasing number of RNE in colectomy during the first decade of the 21st century [8, 13, 14], which supports the results of the trends of RNE using U.S. data. However, the survival results of other populations need to be further verified by more clinicians from different regions.

\section{Conclusions}

The golden period of surgical development in colon cancer, using RNE as an alternative indicator, occurred in the first decade of the 21st century. Although a more extensive lymph node evaluation is able to reduce the risk of underestimated staging, increasing RNE does not provide survival benefits for locoregional colon cancer. A cautious reduction in the scope of lymph node dissection may be reasonable for radical surgery of colon cancer.

\section{Synopsis}

This population-based study confirmed one growth period and two platform periods regarding the trend of the number of RNE during colectomy for locoregional colon cancer in the past decades.

Although a more extensive lymph node evaluation is able to reduce the risk of underestimated staging, the increasing RNE cannot provide survival benefits for locoregional colon cancer.

\section{Supplementary Material}

Supplementary tables.

http://www.jcancer.org/v12p2513s1.pdf

\section{Acknowledgements}

This study was supported by the Nature Scientific Foundation of China (Grant No. 81702956); the Strategy-Oriented Special Project of Central South University in China (Grant No. ZLXD2017003); the Natural Science Foundation of Hunan Province
(Grant No. 2020JJ4903 and 2020JJ5920); The 12th FiveYear Plan of Education Science in Hunan Province (XJKO11BGD032); and The Colorectal cancer medical seed research fund project named "Effect and mechanism of YAP1 on EGFR resistance in K-ras wild-type metastatic colorectal cancer" from the Beijing Bethune Public Welfare Foundation.

The corresponding author, Yuqiang Li, gratefully acknowledges financial support from China Scholarship Council.

\section{Data availability statement}

These data were derived from the Surveillance, Epidemiology and End Results (SEER) database (https://seer.cancer.gov/) and identified using the SEER*Stat software (Version 8.3.5) (https://seer. cancer.gov/seerstat/).

\section{Ethics approval}

Approval from the ethical board for this study was not required because of the public nature of all the data.

\section{Informed consent}

Patients' informed consent was waived because of the retrospective nature of the study design.

\section{Author Contributions}

Zhongyi Zhou, Yuqiang Li and Haiping Pei conceived and designed the study. Zhongyi Zhou wrote the article. Lilan Zhao downloaded and screened the data from SEER database. All authors participated in analyzing the data. All authors read and approved the final manuscript.

\section{Competing Interests}

The authors have declared that no competing interest exists.

\section{References}

1. Li Destri G, Di Carlo I, Scilletta R, Scilletta B, Puleo S. Colorectal cancer and lymph nodes: the obsession with the number 12. World journal of gastroenterology. 2014; 20: 1951-60.

2. Le Voyer TE, Sigurdson ER, Hanlon AL, Mayer RJ, Macdonald JS, Catalano PJ, et al. Colon cancer survival is associated with increasing number of lymph nodes analyzed: a secondary survey of intergroup trial INT-0089. Journal of clinical oncology: official journal of the American Society of Clinical Oncology. 2003; 21: 2912-9.

3. Washington MK, Berlin J, Branton P, Burgart LJ, Carter DK, Fitzgibbons PL, et al. Protocol for the examination of specimens from patients with primary carcinoma of the colon and rectum. Archives of pathology \& laboratory medicine. 2009; 133: 1539-51.

4. Tagliacozzo S, Tocchi A. Extended mesenteric excision in right hemicolectomy for carcinoma of the colon. International journal of colorectal disease. 1997; 12: 272-5.

5. Budde CN, Tsikitis VL, Deveney KE, Diggs BS, Lu KC, Herzig DO. Increasing the number of lymph nodes examined after colectomy does not improve colon cancer staging. Journal of the American College of Surgeons. 2014; 218: 1004-11.

6. Hohenberger W, Weber K, Matzel K, Papadopoulos T, Merkel S. Standardized surgery for colonic cancer: complete mesocolic excision and central ligationtechnical notes and outcome. Colorectal disease: the official journal of the Association of Coloproctology of Great Britain and Ireland. 2009; 11: 354-64; discussion 64-5. 
7. West NP, Hohenberger W, Weber K, Perrakis A, Finan PJ, Quirke P. Complete mesocolic excision with central vascular ligation produces an oncologically superior specimen compared with standard surgery for carcinoma of the colon. Journal of clinical oncology: official journal of the American Society of Clinical Oncology. 2010; 28: 272-8

8. van Erning FN, Crolla RM, Rutten HJ, Beerepoot LV, van Krieken JH, Lemmens VE. No change in lymph node positivity rate despite increased lymph node yield and improved survival in colon cancer. European journal of cancer. 2014; 50: 3221-9.

9. Li Y, Zhao L, Gungor C, Tan F, Zhou Z, Li C, et al. The main contributor to the upswing of survival in locally advanced colorectal cancer: an analysis of the SEER database. Therapeutic advances in gastroenterology. 2019; 12: 1756284819862154

10. Nelson H, Petrelli N, Carlin A, Couture J, Fleshman J, Guillem I, et al. Guidelines 2000 for colon and rectal cancer surgery. Journal of the National Cancer Institute. 2001; 93: 583-96.

11. Garcia B, Guzman C, Johnson C, Hellenthal NJ, Monie D, Monzon JR. Trends in lymph node excision and impact of positive lymph node ratio in patients with colectomy for primary colon adenocarcinoma: Population based study 1988 to 2011. Surgical oncology. 2016; 25: 158-63.

12. Dubecz A, Solymosi N, Schweigert M, Stadlhuber RJ, Peters JH, Ofner D, et al. Time trends and disparities in lymphadenectomy for gastrointestinal cancer in the United States: a population-based analysis of 326,243 patients. Journal of gastrointestinal surgery: official journal of the Society for Surgery of the Alimentary Tract. 2013; 17: 611-8; discussion 8-9.

13. Bernhoff R, Holm T, Sjövall A, Granath F, Ekbom A, Martling A. Increased lymph node harvest in patients operated on for right-sided colon cancer: a population-based study. Colorectal disease: the official journal of the Association of Coloproctology of Great Britain and Ireland. 2012; 14: 691-6.

14. O'Shea A, Aly O, Parnaby CN, Loudon MA, Samuel LM, Murray GI. Increased lymph node yield in colorectal cancer is not necessarily associated with a greater number of lymph node positive cancers. PloS one. 2014; 9: e104991.

15. Chang GJ, Rodriguez-Bigas MA, Skibber JM, Moyer VA. Lymph node evaluation and survival after curative resection of colon cancer: systematic review. Journal of the National Cancer Institute. 2007; 99: 433-41.

16. Bokey L, Chapuis PH, Chan C, Stewart P, Rickard MJ, Keshava A, et al. Long-term results following an anatomically based surgical technique for resection of colon cancer: a comparison with results from complete mesocolic excision. Colorectal disease : the official journal of the Association of Coloproctology of Great Britain and Ireland. 2016; 18: 676-83.

17. Bertelsen CA, Neuenschwander AU, Jansen JE, Wilhelmsen $M$, Kirkegaard-Klitbo A, Tenma JR, et al. Disease-free survival after complete mesocolic excision compared with conventional colon cancer surgery: a retrospective, population-based study. The Lancet Oncology. 2015; 16: 161-8.

18. Reha J, Mukkamalla SKR, Rathore R, Somasundar PS. Adequate lymph node evaluation in the elderly is associated with improved survival in patients with stage I-III colon cancer: A validation study using the National Cancer Data Base. European journal of surgical oncology : the journal of the European Society of Surgical Oncology and the British Association of Surgical Oncology. 2018; 44: 148-56

19. Bertelsen CA, Neuenschwander AU, Jansen JE, Tenma JR, Wilhelmsen M, Kirkegaard-Klitbo A, et al. 5-year outcome after complete mesocolic excision for right-sided colon cancer: a population-based cohort study. The Lancet Oncology. 2019; 20: 1556-65.

20. Modulation of fluorouracil by leucovorin in patients with advanced colorectal cancer: evidence in terms of response rate. Advanced Colorectal Cancer Meta-Analysis Project. Journal of clinical oncology: official journal of the American Society of Clinical Oncology. 1992; 10: 896-903.

21. Gunderson LL, Jessup JM, Sargent DJ, Greene FL, Stewart AK. Revised TN categorization for colon cancer based on national survival outcomes data. Journal of clinical oncology: official journal of the American Society of Clinical Oncology. 2010; 28: 264-71.

22. Agalianos C, Gouvas N, Dervenis C, Tsiaoussis J, Theodoropoulos G, Theodorou D, et al. Is complete mesocolic excision oncologically superior to conventional surgery for colon cancer? A retrospective comparative study. Annals of gastroenterology. 2017; 30: 688-96.

23. Zhou J, Guo Z, Yu W, Li S, Qiao W. Clinical Evaluation of Preoperative Radiotherapy Combined with FOLFOX Chemotherapy on Patients with Locally Advanced Colon Cancer. The American surgeon. 2019; 85: 313-20.

24. Deng Y, Chi P, Lan P, Wang L, Chen W, Cui L, et al. Modified FOLFOX6 With or Without Radiation Versus Fluorouracil and Leucovorin With Radiation in Neoadjuvant Treatment of Locally Advanced Rectal Cancer: Initial Results of the Chinese FOWARC Multicenter, Open-Label, Randomized Three-Arm Phase III Trial. Journal of clinical oncology: official journal of the American Society of Clinical Oncology. 2016; 34: 3300-7. 